\title{
Diurnal and seasonal behavior of the Hokkaido East SuperDARN ground backscatter: simulation and observation
}

\author{
Alexey V. Oinats ${ }^{1 *}$, Nozomu Nishitani ${ }^{2}$, Pavlo Ponomarenko ${ }^{3,4}$ and Konstantin G. Ratovsky ${ }^{1}$
}

\begin{abstract}
We studied regular diurnal and seasonal behaviors of ground backscatter propagation characteristics corresponding to the Hokkaido East Super Dual Auroral Radar Network (SuperDARN) (43.53 N, $143.61^{\circ}$ E). Firstly, we simulated key propagation characteristics using a high frequency (HF) calculation technique based on the waveguide approach and International Reference lonosphere (IRI)-2012 model as background ionosphere. The minimum slant range, skip distance, corresponding elevation angle, and true reflection height were considered in this study. The behaviors of these characteristics were well explained by diurnal and seasonal variations in the critical frequency and maximum height of corresponding ionosphere layer in HF reflection point. We estimated the accuracy of the standard SuperDARN mapping technique and proposed a means for its improvement. Secondly, we constructed an algorithm for mass data processing and extracted diurnal dependencies of the minimum slant range, corresponding elevation angle, and effective reflection height from the Hokkaido East SuperDARN dataset for a period from 2007 to 2014. The algorithm uses the simulated characteristics for distinguishing regular ground backscatter echoes propagating in the E and F2 HF channels. Observed monthly mean and simulated values of the characteristics were compared, and the result showed that the accuracy of IRI-2012 significantly depends on solar activity level and orientation of HF propagation path. In general, the difference between observed and simulated values decreased with increases in solar activity and azimuth. We also analyzed the occurrence of echoes originating behind the radar and found that they most frequently appear in winter and equinoxes before sunrise in beam \#0 and after sunset in beam \#15. The probability of their observation for a specific local time could reach up to $35 \%$.
\end{abstract}

Keywords: High-frequency wave ionospheric propagation, International reference ionosphere, Hokkaido East SuperDARN radar

\section{Introduction}

Super Dual Auroral Radar Network (SuperDARN; Chisham et al. 2007) is currently the widest highfrequency (HF) $(8-20 \mathrm{MHz})$ radar network that actively utilizes ground backscatter (GB) to study ionospheric processes. The use of GB has been given special importance with the extension of the SuperDARN to midlatitudes (Baker et al. 2007), where the percentage of ionospheric coherent echoes is sufficiently lower in comparison with polar and sub-polar regions. In contrast to

\footnotetext{
*Correspondence: oinats@iszf.irk.ru

'Institute of Solar-Terrestrial Physics SB RAS, 664033, Lermontov st., 126a, P.O. Box 291, Irkutsk, Russia

Full list of author information is available at the end of the article
}

ionospheric echoes, GB has a more regular and predictable behavior and can be successfully used for different scientific and applied purposes, such as monitoring HF propagation condition (Hughes et al. 2002; Bland et al. 2014), testing ionosphere models, and studying traveling ionospheric disturbances (Samson et al. 1990; Bristow et al. 1994; Karhunen et al. 2006; Chisham et al. 2007). The multimode character of GB, which is related to the multihop propagation mechanism and appearance of several HF waveguides, creates difficulties in automatic interpretation of radar data. Another limiting factor is the relatively low accuracy of GB mapping related to HF wave refraction caused by different regular (diurnal and seasonal ionosphere variations, solar activity) and
望 Springer

(C) 2016 Oinats et al. Open Access This article is distributed under the terms of the Creative Commons Attribution 4.0 International License (http://creativecommons.org/licenses/by/4.0/), which permits unrestricted use, distribution, and reproduction in any medium, provided you give appropriate credit to the original author(s) and the source, provide a link to the Creative Commons license, and indicate if changes were made. 
irregular conditions (ionospheric disturbances, geomagnetic activity). Measurement of the elevation angle allows advancements in efficiently solving the mentioned problems (Milan et al. 1997). However, the shortcomings arising from regular ionospheric gradients and the lack of accuracy in mapping techniques remain in the latter case too.

One solution for considering the regular factors is the simulation of HF GB using modern ionosphere models. Such a simulation allows us to estimate the degree of influence of different factors and also to develop reliable algorithms for separating different propagation modes. The comparison of simulation results with observational data might be useful in testing and improving the corresponding ionosphere models.

In the present study, we simulated the diurnal and seasonal behaviors of key GB characteristics such as the minimum slant range, skip distance, corresponding elevation angle, and true height of HF reflection. All calculations are provided by using an original HF wave calculation technique based on the waveguide approach and global reference ionosphere model International Reference Ionosphere (IRI)-2012 (Bilitza et al. 2014). Analyzing the simulation results, we discuss the accuracies of data mapping and the inversion of ionospheric critical frequency. Automated processing of the Hokkaido East SuperDARN dataset for a period from 2007 to 2014 allowed us to compare simulated characteristics with observed monthly mean and to evaluate the accuracy of IRI-2012 during different seasons and local times, under different levels of solar activity and orientations of HF propagation path.

\section{Ground backscatter calculation technique}

HF GB was simulated using an original calculation technique (Oinats et al. 2012) developed at the Institute of Solar-Terrestrial Physics (ISTP SB RAS) and based on an adiabatic approach of the eigenfunction method. In case of an azimuthally symmetric Earth-ionosphere waveguide, the electromagnetic field induced by emitter with an arbitrary current distribution is expressed by a series of eigenfunctions:

$$
E(\vec{r}, t) \propto \operatorname{Re}\left\{\sum_{n} I_{n}(\phi) A_{n}(\vec{r}) g_{0}\left(t-\tau_{n}(\vec{r})\right) e^{i \Phi_{n}(\vec{r})-i \omega_{0} t}\right\}
$$

In Eq. (1), we use the spherical coordinate system with origin in the center of the Earth; $\vec{r}=\{r, \theta, \phi\}$ is the radius vector of the observation point inside a waveguide; $\omega_{0}$ is the cyclic operating frequency; $\tau_{n}(\vec{r}), A_{n}(\vec{r})$, and $\Phi_{n}(\vec{r})$ are the time lag, amplitude, and phase of the eigenfunction with number $n$, respectively; $g_{0}(t)$ is the time envelope of a transmitted pulse; and $I_{n}(\phi)$ is the excitation coefficient, which is determined by the characteristics of emitters or scattering features of rough ground surfaces (Kurkin et al. 1990). We have not provided full equations for time lag, amplitude, and phase of eigenfunction because of their bulkiness.

Equation (1) allows the calculations of the spatialtemporal distribution of the HF amplitude everywhere inside the waveguide. The summation in Eq. (1) was carried out for a fraction of eigenfunctions that are effectively excited by the emitter and weakly penetrate through the ionosphere (Oinats et al. 2012). The fraction consists of several thousands of eigenfunctions in case of the HF channel where the F2 layer represents the upper waveguide boundary. We used a special stationary condition describing the eigenfunction phase to make the calculation more effective. The stationary condition represents interference features of the eigenfunction series:

$$
L_{n}^{ \pm}\left(\vec{r}, \omega_{0}\right)=\frac{1}{2 \pi}\left(\Phi_{n}^{ \pm}(\vec{r})-\Phi_{n+1}^{ \pm}(\vec{r})\right)=l^{ \pm}
$$

where $l^{ \pm}$is the integer value representing the number of hops. Equation (2) defines a fraction of phased eigenfunctions and allows us to determine HF propagation modes and to calculate key propagation characteristics.

In this study, we investigated the diurnal and seasonal dependence of the one-hop GB. We considered HF propagation characteristics such as the minimum slant range, skip distance, elevation angle, true reflection height, slant range, and ground distance to the ionospheric reflection point (turning point). We simulated the characteristics taking into account the specifications of the Hokkaido East radar for the entire operating period from 2007 to 2014. We used the IRI-2012 model with the "storm" option disabled. The diurnal dependence of the above characteristics was calculated with a temporal resolution of $1 \mathrm{~h}$ for the 15th day of each month for each of the 16 radar beams and a set of the most usable operating frequencies.

\section{Simulation results and application}

Figure 1 shows diurnal and seasonal dependencies of the minimum slant range (1a), corresponding elevation angle (1b), and true reflection height (1c) for beam \#0 of the Hokkaido East radar (azimuth of $5.7^{\circ}$ clockwise from the north direction). The dependencies correspond to an operating frequency of $11 \mathrm{MHz}$ and are shown for 2 years of low and high solar activities, which are 2010 and 2014, respectively. Echoes propagating in different HF channels (E, F1, and F2) were separated by checking the true reflection height. Figure 1d, e presents dependencies of the critical frequency and maximum height for the electron density profile corresponding to the 


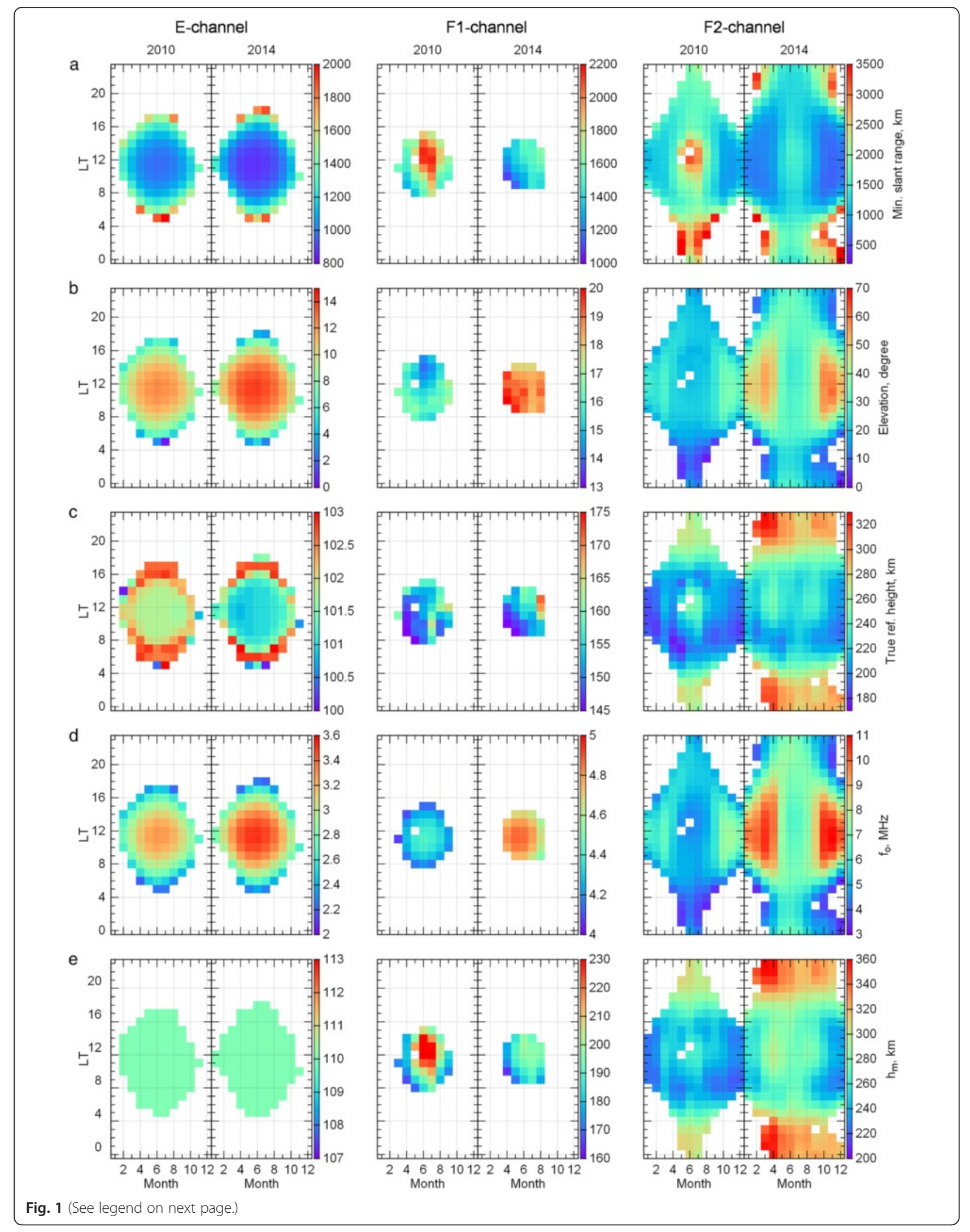


(See figure on previous page.)

Fig. 1 Diurnal and seasonal behavior of the simulated HF GB characteristics and corresponding ionosphere parameters. Left, middle, and right columns correspond to the E, F1, and F2 channels, respectively. Panels show the variations of the following characteristics: a minimum slant range, $\mathbf{b}$ elevation angle, $\mathbf{c}$ true reflection height, and $\mathbf{d}$, e critical frequency and maximum height for electron density profile at the reflection region. Simulated data presented for beam \#0 of the Hokkaido East SuperDARN, at an operating frequency of 11 MHz for 2 years, 2010 and 2014. Hereinafter, each characteristic is color-coded according to the bar to the right of the panel; local time and month are shown on the vertical and horizontal axes, respectively

coordinates of the ionospheric reflection point. The empty cells have no GB, as shown in Fig. 1. In the E and F1 channels, there is no GB in the nighttime for an entire year, in the daytime in winter, and partially during equinox. In the F2 channel, there is no GB during nighttime in winter. This phenomenon can be explained by decreases in the critical frequency below some level when the HF wave completely passes through the ionosphere without reflection (at any given elevation angle). With increases in solar activity, the local time interval of GB "absence" decreased in the F2 channel, increased in the F1 channel, and remained almost the same in the E channel.

\section{Minimum slant range and skip distance}

The diurnal minimum of the slant range in the $\mathrm{E}$ channel was seen near noon (see left column of Fig. 1a). In the morning and evening, reflection from the layer occurred farther from the radar due to the lower critical frequency (see left column of Fig. 1d) and the corresponding slant range increased accordingly. The minimum slant range in the F2 channel showed a similar behavior in winter and equinox (see right column of Fig. 1a). However, for the F2 layer, decreases in the critical frequency were often accompanied by increases in the maximum height (and vice versa). Therefore, the slant range varied more rapidly in the F2 channel than in the $\mathrm{E}$ channel. There were two local maximums in the diurnal dependence of slant range in summer. In addition to the nighttime maximum, there was a maximum near noon. The latter became most prominent under low solar activity. During the minimum of solar activity, the critical frequency of summer daytime F2 layer decreased to the values corresponding to the $\mathrm{E}$ and F1 layers. This can lead to a partial or total screening of the F2 channel. In Fig. 1a, the F1 layer screens the F2 channel at 13 LT in June 2010, and the E layer screens both the F1 and F2 channels at 12 LT in May 2010.

A post-noon maximum is a feature of the minimum slant range in the F1 channel. The maximum became prominent under low solar activity. In Fig. 1e (middle column), the drastic increase in slant range is related with the significant increase in the $\mathrm{F} 1$ maximum height (up to the values of the F2 layer maximum height).

In general, the minimum slant range noticeably decreased with increases in solar activity. Under high solar activity, the critical frequencies became higher, the reflection from the layer occurred closer to the radar, and the corresponding slant range decreased. In case of the F2 channel, the decrease in slant range was partially compensated by a general lifting of the F2 layer (increases in the maximum height).

The behavior of the minimum slant range was repeated in detail in the seasonal and diurnal dependencies of the skip distance. The difference between the two characteristics varied in the following ranges: $\sim 20$ $50 \mathrm{~km}$ in the E channel, $\sim 80-150 \mathrm{~km}$ in the F1 channel, and $\sim 100-200 \mathrm{~km}$ in the F2 channel.

\section{Elevation angle}

In Fig. 1b, the diurnal and seasonal dependence of the elevation angle repeated the corresponding critical frequency behavior (Fig. 1d); the higher the critical frequency, the higher the elevation angle. This phenomenon directly follows Snell's law (Davies 1990). In case of a flat ionosphere, a relation between the oblique and vertical sounding frequencies, $f_{\text {oblique }}$ and $f_{\text {vert }}$, when the waves are reflected at the same true height, is given by $f_{\text {oblique }}=f_{\text {vert }} / \cos \theta_{0}$. Here, $\theta_{0}$ is the incidence angle measured from a normal to the ionosphere layer. The above relation can also be rewritten as

$$
f_{\text {oblique }}=f_{\text {vert }} / \sin \Delta
$$

Here, $\Delta$ is the elevation angle. Elevation measurements could be used for estimation of the plasma frequency in the reflection point (Hughes et al. 2002; Bland et al. 2014). Equation (3) is applicable for distances up to about $500 \mathrm{~km}$. For longer distances, we should take into account the roundness of the Earth. A simple equation can be obtained for this case from the generalized Snell's law, but it includes true reflection height as an additional parameter.

\section{True reflection height}

Diurnal and seasonal dependence of the true reflection height in the F1 and F2 channels was determined mostly by the behavior of a corresponding maximum height (see middle and right columns of Fig. 1c, e). The true reflection height was lower than the corresponding maximum height by approximately $40 \mathrm{~km}$. Since the IRI maximum height of the $\mathrm{E}$ layer was fixed at specific 
value of $110 \mathrm{~km}$, variations in the true reflection height were caused only by the critical frequency variation (see left column of Fig. 1c-e). Deviations between the true reflection height and the maximum height of the $\mathrm{E}$ channel varied within a small range of $\sim 6-10 \mathrm{~km}$. The true reflection height in the F1 and F2 channels increased with increases in solar activity (lifting of the layers). On the contrary, the true reflection height in the E channel decreased with increases in solar activity.

\section{Application of the calculated characteristics}

One of the important tasks, in monitoring the ionosphere using SuperDARN radars, is the mapping of the reflecting/scattering regions. In practical terms, while mapping, we should start by determining the effective reflection height. In a spherical ionosphere, assuming that the Breit and Tuve's theorem holds (Davies, 1990), we determined the effective height, $h_{\text {eff: }}$ :

$$
h_{\text {eff }}=\left(a^{2}+r_{\text {ref }}^{2}+2 a r_{\text {ref }} \sin \Delta\right)^{1 / 2}-a
$$

where $a$ is the radius of the Earth and $r_{\text {ref }}$ is the slant range to the reflection point. In case of the absence of the elevation measurement, the effective height is usually assumed to be fixed at a specific value (Bristow et al.
1994; Grocott et al. 2013; Oinats et al. 2015), or some empirical height models could be used (Chisham et al. 2008; Yeoman et al. 2008). Figure 2a shows the dependence of the effective reflection height calculated using Eq. (4). It varied in a wide range from 200 to $500 \mathrm{~km}$ in the F1 and F2 channels and from 115 to $130 \mathrm{~km}$ in the E channel. The intervals did not overlap and therefore, if we could calculate the effective reflection height properly, we would be able to separate the $\mathrm{E}$ echoes from the F (F2 and F1) echoes at least.

Application of the fixed effective height leads to a systematic error in mapping. Here, we could estimate it using the following procedure. First, for some fixed $h_{\text {eff }}$ and certain $r_{\text {ref }}$ from the simulation, we determined an effective elevation angle from Eq. (4). Further, using the effective angle and $r_{\text {ref }}$, we calculated the ground distance to the reflection point, $D_{\text {ref: }}$ :

$$
D_{\text {ref }}=a \cdot \operatorname{arctg}\left(\frac{r_{\text {ref }} \cos \Delta}{a+r_{\text {ref }} \sin \Delta}\right)
$$

Figure 3a shows the distance offset, which is the difference between the two distances: the first one was calculated by Eq. (5) and the second one was the actual distance from the simulation. The effective height was

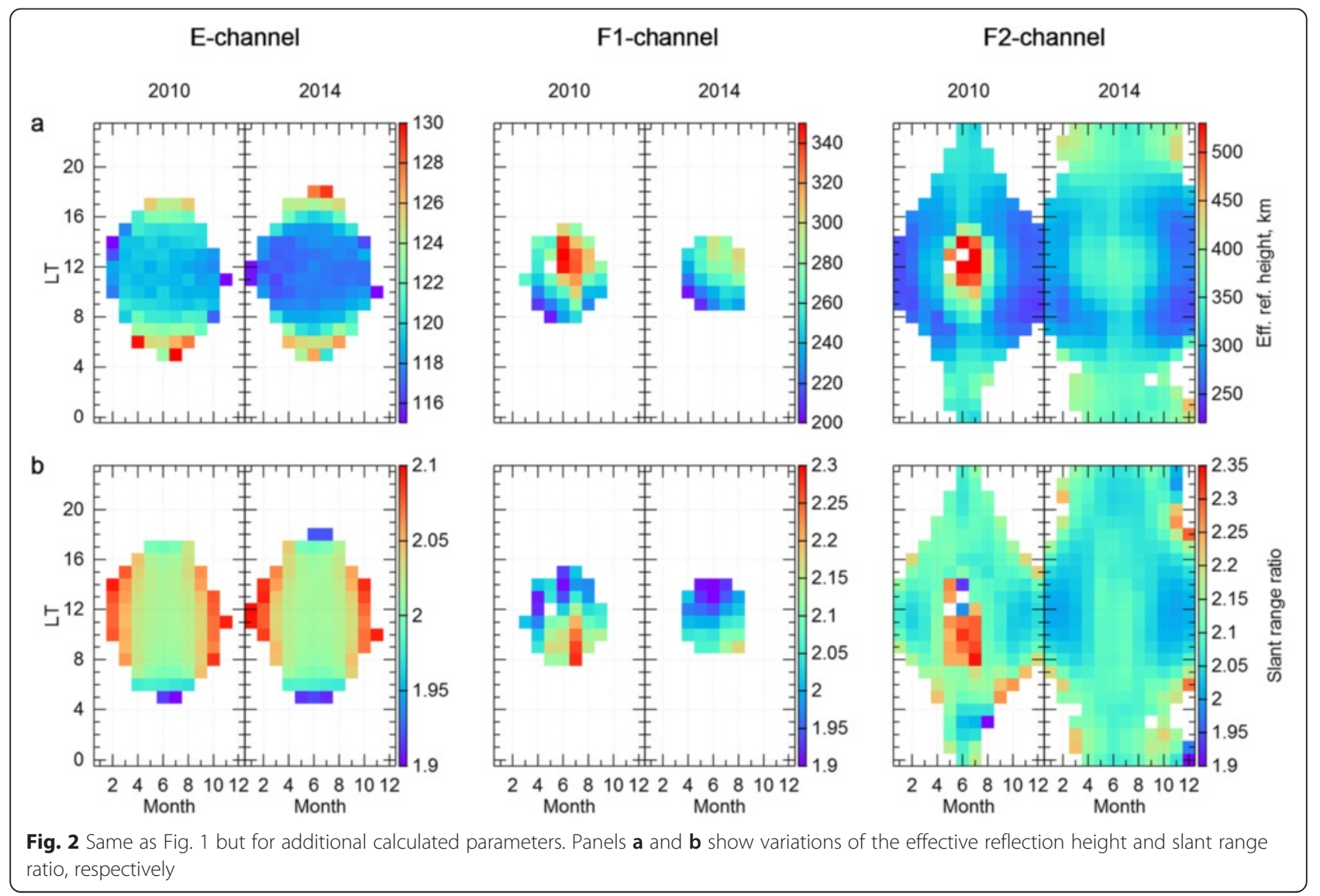




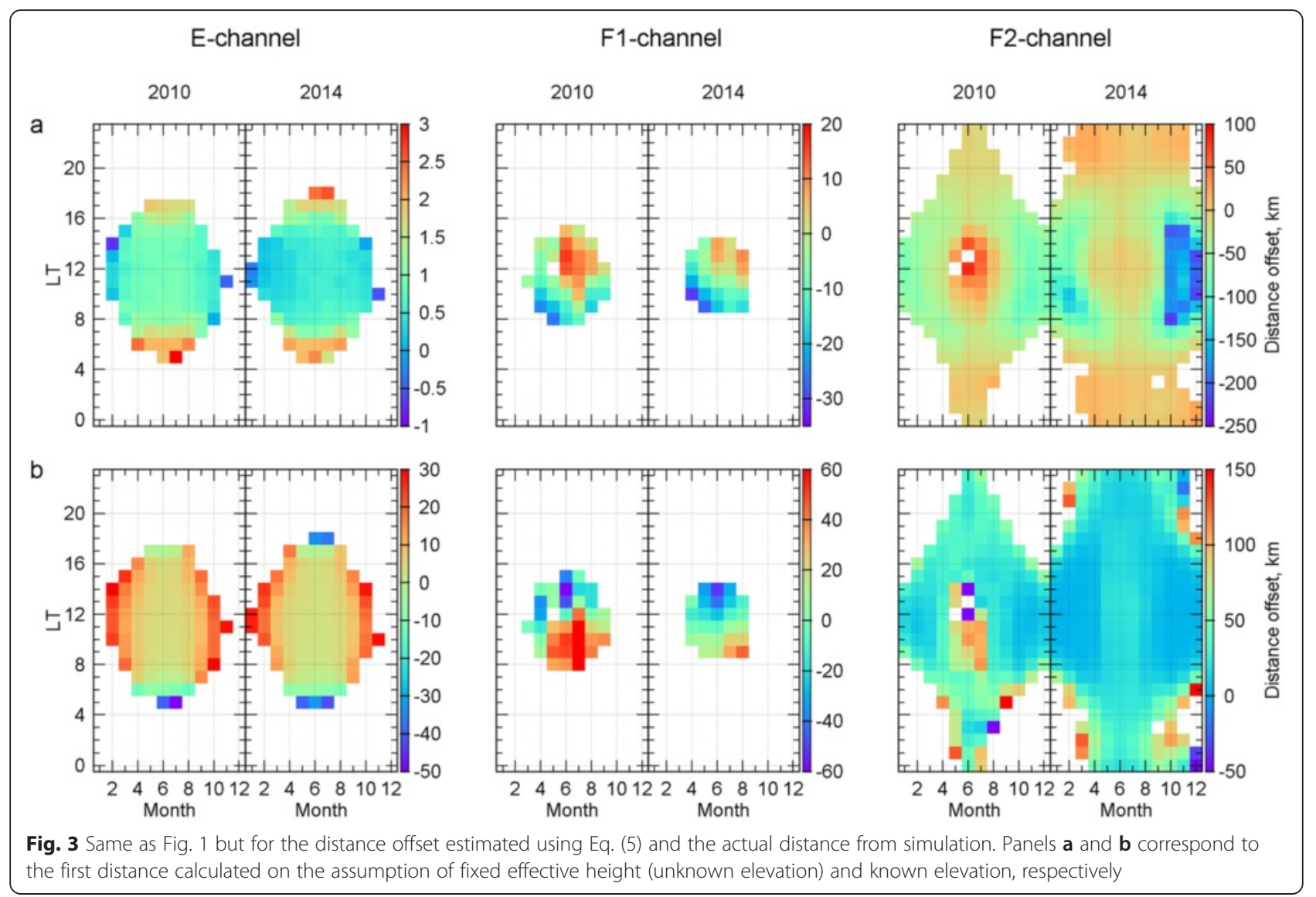

equal to 115,260 , and $350 \mathrm{~km}$ in the $\mathrm{E}, \mathrm{F} 1$, and F2 channels, respectively. The offset in the F2 channel varied in a wide range from $-250 \mathrm{~km}$ in equinox under high solar activity (underestimation) to $100 \mathrm{~km}$ in summer under low solar activity (overestimation). The offset in the $\mathrm{E}$ and F1 channels varied from a few to tens of kilometers.

Using elevation angles, we could significantly minimize the error. However, there was a shortcoming in that HF radar that cannot measure the slant range to the reflection point directly (in case of GB). In practical terms, one often assumes that the reflection point is located in the path middle point, and the slant range to the reflection point is equal to half of the full GB slant range (Bristow et al. 1994; He et al. 2004). This is correct for the spherical ionosphere. However, in general cases, the reflection point can significantly move out from the middle point due to ionospheric gradient along the propagation path. Figure $2 \mathrm{~b}$ shows a ratio between the full slant range and the slant range to the reflection point. The ratio is usually greater than two. Since beam $\# 0$ is oriented towards the North, it usually has negative electron density gradients. The greatest gradients would appear at local times when the solar terminator passes through the propagation path. However, as shown in
Fig. $2 b$ (right column), the ratio reaches values of $\sim 2.3$ even during daytime under low solar activity (the F1 layer was lifted to the heights of the F2 layer during this period). Figure $3 \mathrm{~b}$ illustrates a systematic error due to regular gradients. The offset is shown for the distance calculated by Eq. (5) using the elevation angle and $r_{\text {ref }}=$ $r_{\text {full }} / 2$, where $r_{\text {full }}$ is the full GB slant range from the simulation (see Fig. 1a). The offset varied on average from 0 to $100 \mathrm{~km}$ in the $\mathrm{F} 2$ channel (overestimation). It reached values of $\pm 30 \mathrm{~km}$ and of $\pm 60 \mathrm{~km}$ in the $E$ and F1 channels, respectively. To reduce the latter error while mapping, the use of the simulated slant range ratio might be effective (Fig. 2b).

Another important task is the estimation of the critical frequency of the ionosphere. Using the generalized Snell's law in the spherical ionosphere (Davis 1990), the plasma frequency, $f_{p}$, can be determined in the reflection point by

$$
f_{p}=f_{\text {oblique }}\left(1-\left(\frac{\cos \Delta}{1+h_{\text {true }} / a}\right)^{2}\right)^{1 / 2}
$$

Here, $h_{\text {true }}$ is the true reflection height. Figure $4 a$ shows the ratio (red scatter plot) between the frequency 

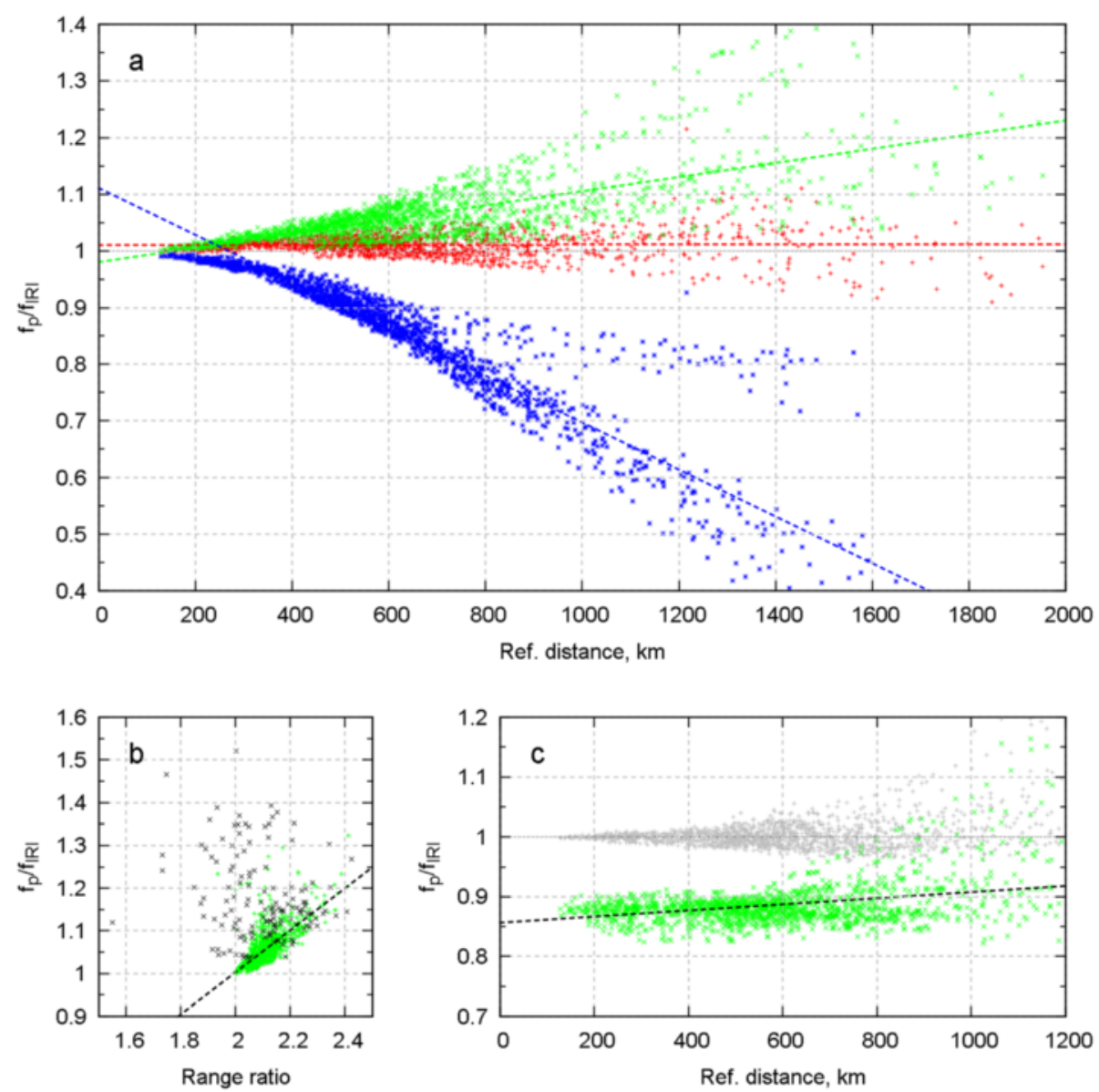

Fig. 4 Ratio between the estimated and actual plasma frequencies in the reflection point. In panel a, red, blue, and green dots correspond to the estimation using Eq. (6), Eq. (3), and Eq. (7), respectively. Distance to the reflection point is shown on the horizontal axes. In panel $\mathbf{b}$, dots show the relationship between the frequency ratio estimated by Eq. (6) and the slant range ratio. Green/black dots correspond to distances shorter/ longer than $1200 \mathrm{~km}$. In panel c, gray dots correspond to the estimation using Eq. (8). Green dots show the ratio between estimated plasma frequency using Eq. (8) and the actual critical frequency of the F2 layer. Distance to the reflection point is shown on the horizontal axes. Dashed lines show linear regressions

calculated from Eq. (6) and the actual plasma frequency in the simulation (from IRI-2012) for the F2 channel and entire period from 2007 to 2014. The distance from the radar location to the reflection point is shown on the horizontal axis. The dispersion of the scatter plot increased with increases in distance. However, it did not exceed $10 \%$ (from 0.9 to 1.1 ) for distances up to $2000 \mathrm{~km}$. The blue dots showed a similar frequency ratio except for the first frequency calculated by Eq. (3). It is clear that Eq. (3) significantly underestimates the plasma frequency in the reflection point starting from about $500 \mathrm{~km}$.

In practical terms, application of Eq. (6) is difficult because the true reflection height is unknown. To overcome this shortcoming, the effective height, Eq. (4), can be used instead of the true height. In this case, Eq. (6) can be rewritten as

$$
f_{p} \approx f_{\text {oblique }} \sin \left(\Delta+\frac{D_{\text {ref }}}{a}\right)
$$

A scatter plot for the ratio calculated using Eq. (7) is shown in Fig. 4a using green dots. Equation (7) on average gave better correspondence than those of Eq. (3) for distances longer than $500 \mathrm{~km}$. The colored lines show the linear regression of the corresponding scatter plots. The green line did not exceed the accuracy of $10 \%$ ( 1.1 on figure) up to $\sim 1000 \mathrm{~km}$, but the blue line had only $30 \%$ ( $\sim .7$ on figure) at that distance.

It is interesting to refer to the branches of the dots with gradients that are different from the average gradient shown by the lines in Fig. 4a (shallower gradient for the blue branch and steeper gradient for the green dots). These dots correspond the abovementioned period of the post-noon "lifting" of the F1 layer. During this 
period, the ionosphere gradients make some "compensation" for the Earth curvature. That is why the accuracy for these two branches is comparable in absolute values (or the accuracy of the blue branch appeared to be even better than of the green branch for distances longer than $1000 \mathrm{~km}$ ). Such a lifting is a feature of low solar activity in summer post-noon. The number of dots in the branches did not exceed $4 \%$ of the entire number of dots in the scatter plot; therefore, its influence was negligible.

The main contribution to a systematic error in Eq. (7) was the ionosphere gradients along the propagation path. Figure $4 \mathrm{~b}$ shows the relationship between the frequency ratio (calculated using Eq. (7)) and the slant range ratio (Fig. $2 \mathrm{~b}$ ). The green dots correspond to distances up to $1200 \mathrm{~km}$, and the black dots correspond to longer distances. The black line is a linear regression calculated for the fraction of green dots. It is clear that the regression coefficient is very close to the value of 2 . Thus, we can clarify Eq. (7) by

$$
\begin{aligned}
f_{p} & \approx 2 \frac{r_{\text {ref }}}{r_{\text {full }}} f_{\text {oblique }}\left(1-\left(\frac{\cos \Delta}{1+h_{\text {eff }} / a}\right)^{2}\right)^{1 / 2} \\
& =2 \frac{r_{\text {ref }}}{r_{\text {full }}} f_{\text {oblique }} \sin \left(\Delta+\frac{D_{\text {ref }}}{a}\right)
\end{aligned}
$$

Equation (8) reduces the systematic error of Eq. (7) by a factor of 2 for distances lower than $1200 \mathrm{~km}$ (gray dots in Fig. 4c).

As mentioned earlier, the true reflection height was lower than the maximum height of the ionosphere layer; therefore, the frequency defined by Eq. (5) did not correspond to the critical frequency of the layer. Green dots on Fig. 4c show the ratio between the frequency calculated by Eq. (8) and the actual critical frequency of the F2 layer (from IRI-2012). It is clear that the frequency defined by Eq. (8) is lower than the actual critical frequency by $10-15 \%$.

\section{Comparison with observations and discussion}

\section{Data processing}

We constructed a model of the Hokkaido East GB characteristics (Hok-GBM) based on the simulation results presented above. Using Hok-GBM, all described characteristics could be calculated for certain beam, local time, and date within a period from 2007 to 2014. The characteristics for an arbitrary day of a month and local time were calculated using the linear interpolation between two neighbor values. Using Hok-GBM, we processed the Hokkaido East radar data for the entire operating period. The automated procedure for mass data processing involved two main steps.
In the first step, we extracted temporal variations of the minimum slant range, corresponding elevation angle, and effective reflection height (Eq. (4)) of one-hop GB echoes. GB echoes were identified using the standard technique (Blanchard et al. 2009). Echoes originating behind the radar were excluded by analyzing interferometer data (Milan et al. 1997). Our technique for identification of such echoes is very similar to that described in Bland et al. (2014). Note that the elevation angle and range offset were previously calibrated for the Hokkaido East radar by Ponomarenko et al. (2015). To distinguish regular $\mathrm{GB}$ echoes propagating in the $\mathrm{E}$ and F2 channels, we defined a mask including a set of criterion for the slant range, $r_{\text {full }}$, and effective reflection height, $h_{\text {eff. }}$ The bounds were selected on the basis of the above analysis, and they were empirically tested: $100 \mathrm{~km}<h_{\text {eff }}<140 \mathrm{~km}$ and $0.5 \cdot r_{\text {Hok-GBM }}^{E}<r_{\text {full }}<1.4$. $r_{\text {Hok-GBM }}^{E}$ for E channel and $190 \mathrm{~km}<h_{\text {eff }}<600 \mathrm{~km}$ and $0.5 \cdot r_{\mathrm{Hok}-\mathrm{GBM}}^{F 2}<r_{\text {full }}<1.6 \cdot r_{\mathrm{Hok}-\mathrm{GBM}}^{F 2}$ for the F2 channel. Here, $r_{\text {Hok }-G B M}$ is the slant range calculated using HokGBM for corresponding channel, given beam, local time, and date. We searched for the range gate with maximum power within the mask and recorded corresponding slant range, elevation angle, and effective height values.

In the second step, we calculated monthly means of the obtained parameters by averaging the values near the integer local time $( \pm 0.15 \mathrm{~h})$ for each month. We considered only those values that could be associated with quiet geomagnetic conditions $(\mathrm{Kp}<3)$. Monthly means were used for further comparison with the simulated characteristics.

\section{Ground backscatter originating behind the Hokkaido East radar}

Figure 5 shows diurnal and seasonal variation in the relative occurrence rate of echoes originating behind the Hokkaido East radar. The rate of occurrence was calculated by averaging all radar range gates. The dependence of the occurrence rate was distinct. Such echoes most frequently appeared in winter and equinox before sunrise in beam \#0 (white line) and after sunset in beam \#15 (black line). Sunrise and sunset times were calculated at a height of $300 \mathrm{~km}$ and a distance of $500 \mathrm{~km}$ from the radar site. The main reason for the appearance of echoes originating behind the radar is the low critical frequency within the front radar field-of-view (FOV). In this case, the emitted HF waves pass through the ionosphere without reflection. However, a portion of radiated power is always emitted by the radar in the back lobe direction where the critical frequency might be sufficiently high to reflect HF waves. It is obvious that such conditions arise less frequently when the front FOV is illuminated. As shown in Fig. 5, the probability of such 


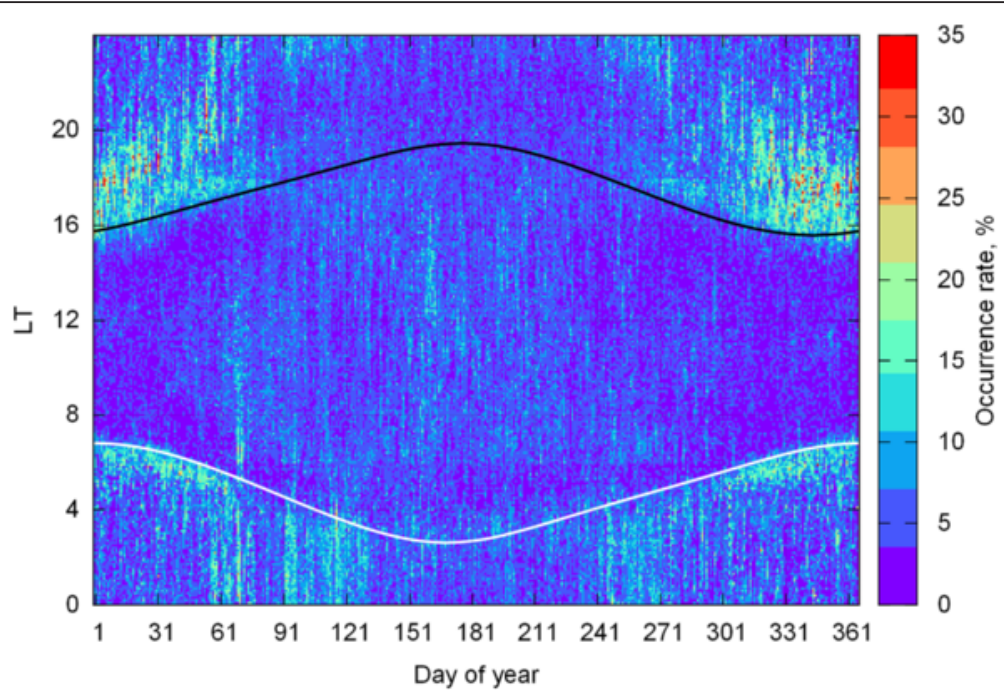

Fig. 5 Diurnal and seasonal variation of the occurrence rate of echoes originating behind the Hokkaido East radar. The white and black lines show sunrise time for beams \#0 and sunset time for beam \#15, respectively

echo observations for a specific local time could reach up to $35 \%$. Therefore, it was actually necessary to take this into account during the radar data mapping.

\section{Monthly mean of the measured characteristics}

Figure 6 shows variations of the observed monthly mean minimum slant range (left), elevation angle (middle), and effective reflection height (right) for beam \#0 in 2010 and 2014. Comparing Figs. 1a, b and 2a, it can be seen that the behavior of the observed characteristics agrees qualitatively with that of the simulations.
However, noticeable morphological differences could be found for the slant range and elevation angle in the F2 channel during daytime in summer and for the effective height in the $\mathrm{E}$ channel during equinox and winter. A distinct summer daytime minimum was not seen in the observed elevation pattern. A distinct summer noon maximum, which was clearly seen in the simulation for low solar activity years, was not seen in the observed slant range pattern. The highest values of the observed effective height in the $\mathrm{E}$ channel during winter and equinox were also not seen in the simulation.

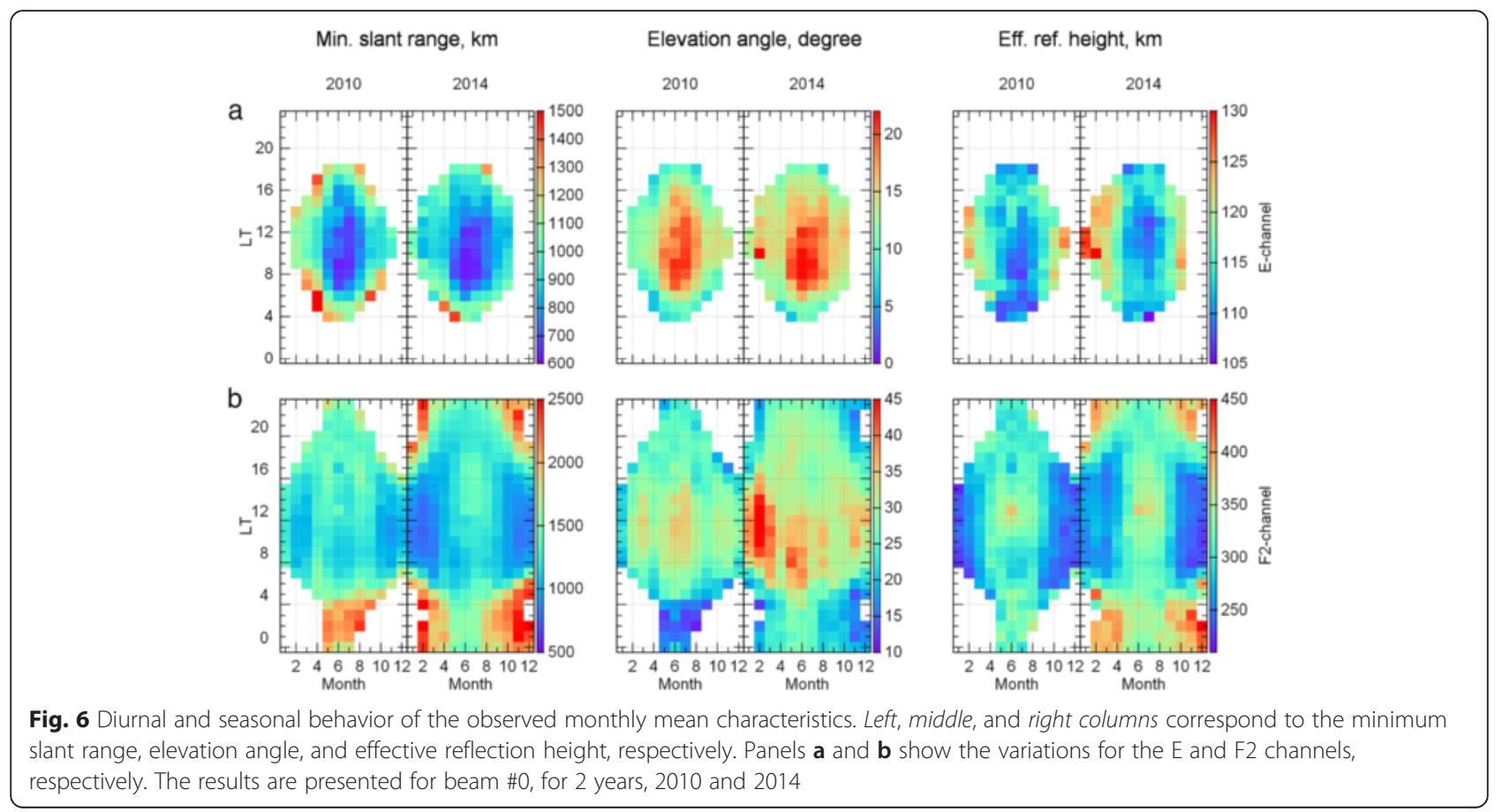


Figure 7 shows the relation between the observed monthly mean (vertical axis) and simulated characteristics (horizontal axis; Hok-GBM) for the entire period. Red, green, and blue color dots correspond to high, moderate, and low solar activity years, respectively. The linear regression and quadratic fit, illustrating general trends, are shown by black and blue bold lines, respectively. Figure 7a shows the scatter plots for the E channel. Hok-GBM in general overestimated the slant range by $\sim 200-300 \mathrm{~km}$ and underestimated the elevation angle by $\sim 5^{\circ}$. This might be related to underestimation of the E layer critical frequency by the IRI model. The observed slant range varied from 550 to $1600 \mathrm{~km}$, whereas the simulated slant range varied from 900 to $2150 \mathrm{~km}$. The observed elevation varied from $7^{\circ}$ to $26^{\circ}$, whereas the simulated angle varied from $3^{\circ}$ to $14^{\circ}$. Although the difference between the observed and simulated effective height did not exceed $20 \mathrm{~km}$, the regression was significantly affected by the fixed maximum height of the $\mathrm{E}$ layer in the IRI model.

Figure $7 \mathrm{~b}$ shows the scatter plots for the F2 channel similar to that of the E channel. Hok-GBM in general overestimated the slant range, which became more noticeable for longer slant ranges. There was a distinct saturation effect in the observed elevation for moderate and high solar activity years. This can be explained by peculiarities of the antenna system such as (1) elevation angle aliasing effect at which the maximum measurable elevation is limited by $45^{\circ}$ (Milan et al. 1997; McDonald et al. 2013; Ponomarenko et al. 2015) and (2) partially by the narrow elevation radiation pattern (it affects the location of the power maximum that the procedure searches in each sounding session). However, the observed effective height on average agreed well with simulated one.

\section{Solar activity and beam number dependence}

To study the Hok-GBM accuracy dependence on solar activity and orientation of the propagation path, we also calculated the yearly mean deviation between the simulated and observed characteristics for each of the 16 beams. The results are presented in Fig. 8. Beam number and year are shown on the horizontal and vertical axes, respectively.

As shown in Fig. 8a, deviation of the slant range in the $\mathrm{E}$ channel in general decreased with year (increases in solar activity), varying from $\sim 320 \mathrm{~km}$ (36 \%) in 2009 to $\sim 200 \mathrm{~km}$ (22\%) in 2012. Deviations of the elevation angle were always negative and varied on average from $-6^{\circ}$ in 2008 to $-4^{\circ}$ in 2012. Negative differences indicated that IRI systematically underestimated the critical frequency of the E layer. The least absolute difference in range and elevation was observed for beams \#2-5 and $\# 11-13$, and the greatest absolute difference was seen for central beams \#7-9.

As shown in Fig. 8b, deviations in the slant range in the F2 channel decreased almost uniformly with year (increase in solar activity) and/or with increases in beam

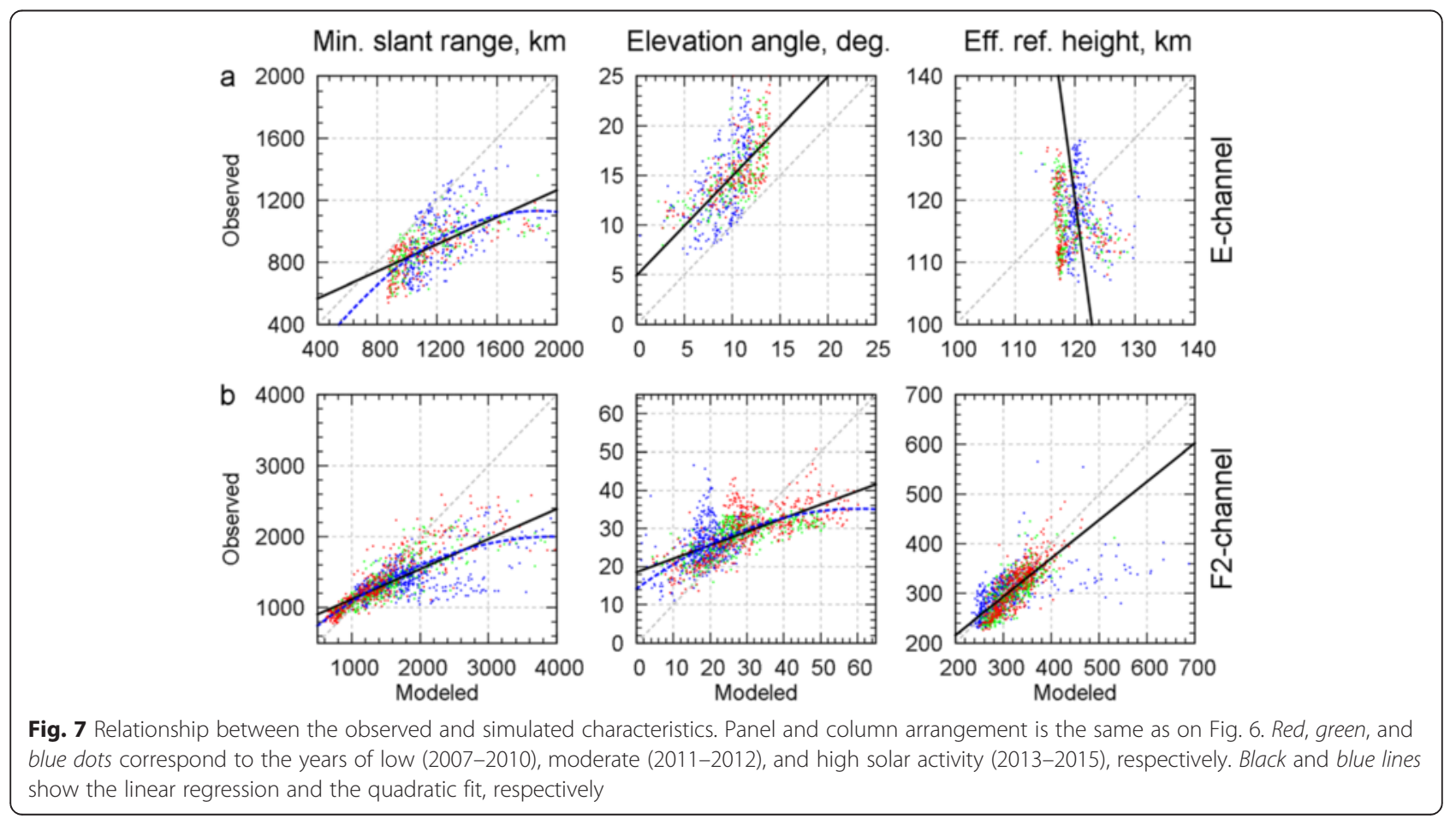




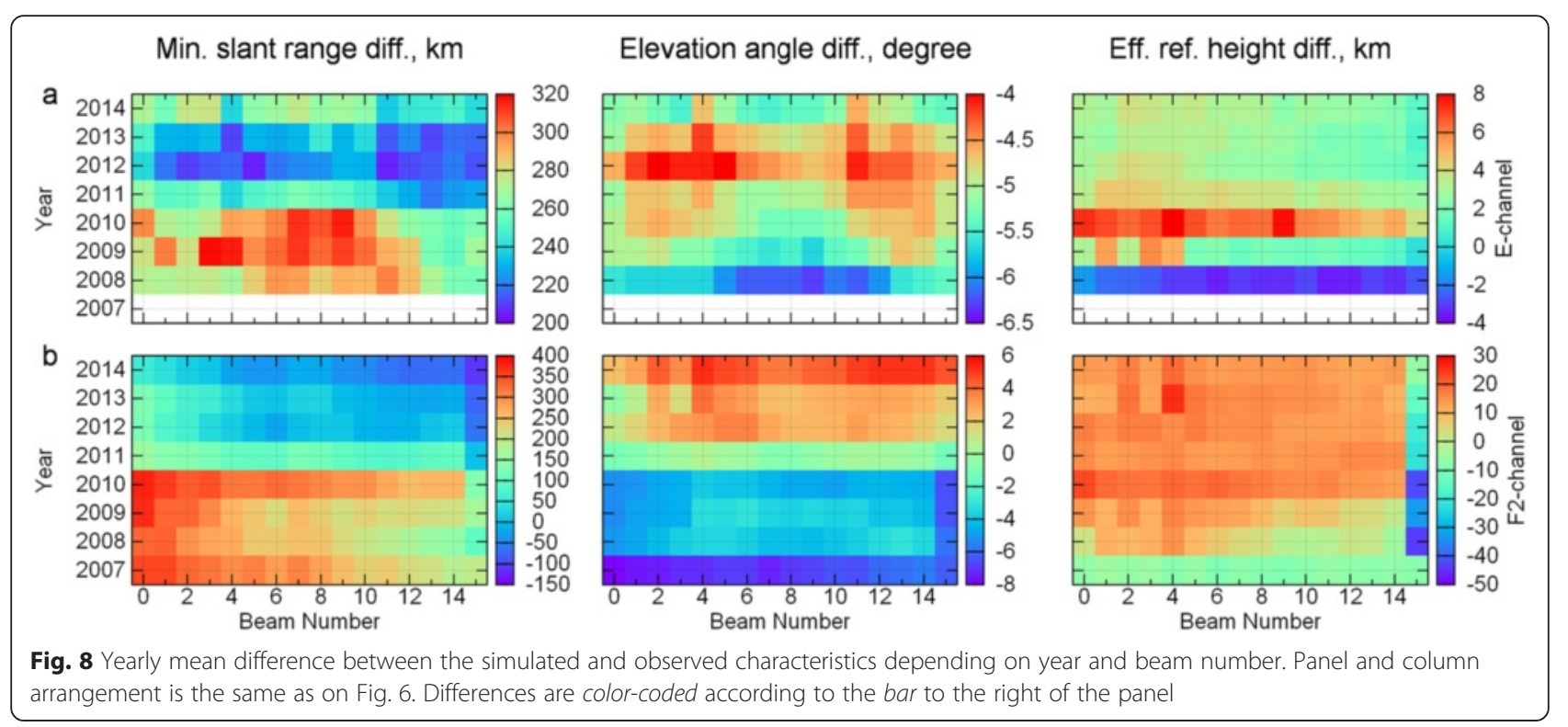

number (increase in azimuth). The greatest difference of $\sim 400 \mathrm{~km}, 30 \%$, (model overestimated) was observed for beam \#0 in 2009 and 2010 (solar activity minimum). The least difference of $-150 \mathrm{~km},-15 \%$, (model underestimated) was observed for beam \#15 in 2014 (solar activity maximum). Deviations of the elevation angle changed almost smoothly with year, varying on average from $-5^{\circ}$ to $4^{\circ}$. The difference was negative/positive for low/high solar activity years (IRI model underestimated/overestimated the critical frequency).

The best agreement was found for the effective reflection height. Its yearly mean deviation varied on average from $-10 \mathrm{~km}$ to $15 \mathrm{~km}$ (from $-15 \%$ to $10 \%$ ) in the F2 channel, and from $-4 \mathrm{~km}$ to $6 \mathrm{~km}$ (from $-3 \%$ to $8 \%$ ) in the $\mathrm{E}$ channel. This means that the deviations of the minimum slant range and elevation angle on average compensate for each other.

\section{Conclusion}

In this paper, we presented the results of GB simulation for an operating period of the 2007-2014 Hokkaido East SuperDARN. The simulation was performed using the original technique based on the waveguide approach and global ionosphere model IRI-2012. We analyzed the diurnal and seasonal behavior of the minimum slant range, elevation angle, and true reflection height. We found that the behavior was well explained by corresponding variations in the critical frequency and maximum height at the reflection point.

Using the simulation results, we studied the accuracy of SuperDARN data mapping. In particular, we showed that assumption of a fixed effective reflection height leads to a systematic error, which varies in a wide range depending on local time, season, and solar activity level.
Application of the elevation measurement could noticeably improve the accuracy of the mapping. In addition, elevation could be applied for estimation of the plasma frequency in the HF reflection region (or even the critical frequency of the layer). The simulated slant range ratio could be used for minimizing the error due to regular ionospheric gradients. In cases without elevation measurement, it is reasonable to use the simulated effective height.

All simulated characteristics were included in the GB model for the Hokkaido East radar (Hok-GBM). The model enables the construction of an automated procedure for mass data processing. Using Hok-GBM, we processed the entire radar dataset and calculated monthly mean of the observed minimum slant range, elevation angle, and effective reflection height. Comparisons showed that the accuracy of IRI-2012 significantly depends on solar activity level and orientation of propagation path. On average, deviations between the observed and simulated values decreased with increases in solar activity.

For the first time, we calculated the rate of occurrence of echoes originating behind the Hokkaido East SuperDARN. We found that such echoes most frequently appear in winter and equinox before sunrise in beam \#0 and after sunset in beam \#15. The probability of such echo observation for a specific local time could reach up to $35 \%$ and should be taken into account during radar data mapping.

\section{Abbreviations}

FOV: field-of-view; GB: ground backscatter; HF: high frequency; Hok-GBM: the Hokkaido radar ground backscatter model; IRI: International Reference Ionosphere; SuperDARN: Super Dual Auroral Radar Network. 


\section{Competing interests}

The authors declare that they have no competing interests.

\section{Authors' contributions}

$\mathrm{AO}$ elaborated the technique of HF GB calculation, provided the processing and calculations, and drafted the manuscript. NN provided the Hokkaido East SuperDARN radar data, supervised the work of AO at STELab. PP implemented the elevation angle calibration. KR proposed the idea of the study. All the authors participated in the discussion and interpretation of the obtained results. All authors have read and approve the final manuscript.

\section{Acknowledgements}

This work was done under financial support from the Russian Foundation for Basic Research (grant no.14-05-00259). The work of Alexey V. Oinats was supported by the Japan Russia Youth Exchange Fellowship Program 2014.

\section{Author details}

${ }^{1}$ Institute of Solar-Terrestrial Physics SB RAS, 664033, Lermontov st., 126a, P.O. Box 291, Irkutsk, Russia. ${ }^{2}$ Institute for Space-Earth Environmental Research, Nagoya University, Furo-cho, Chikusa-ku, Nagoya 464-8601, Japan. ${ }^{3}$ University of Saskatchewan, Saskatoon, SK, Canada. ${ }^{4}$ Solar-Terrestrial Environment Laboratory, (now - Institute for Space-Earth Environmental Research), Nagoya University, Nagoya, Japan.

Received: 31 March 2015 Accepted: 31 December 2015

Published online: 09 February 2016

\section{References}

Baker JBH, Greenwald RA, Ruohoniemi JM, Oksavik K, Gjerloev JW, Paxton LJ, Hairston MR (2007) Observations of ionospheric convection from the Wallops SuperDARN radar at middle latitudes. J Geophys Res 112:A01303

Bilitza D, Altadill D, Zhang Y, Mertens C, Truhlik V, Richards P, McKinnell L-A Reinisch BW (2014) The International Reference lonosphere 2012-a model of international collaboration. J Space Weather Space Clim 4(A07):1-12. doi: $10.1051 /$ swsc/2014004

Blanchard GT, Sundeen S, Baker KB (2009) Probabilistic identification of highfrequency radar backscatter from the ground and ionosphere based on spectral characteristics. Rad Sci 44:RS5012. doi:10.1029/2009RS004141

Bland EC, McDonald AJ, de Larquier S, Devlin JC (2014) Determination of ionospheric parameters in real time using SuperDARN HF radars. J Geophys Res 119(7):5830-5846

Bristow WA, Greenwald RA, Samson JC (1994) Identification of high-latitude acoustic gravity wave sources using the Goose Bay HF radar. J Geophys Res 99(A1):319-331

Chisham G, Lester M, Milan SE, Freeman MP, Bristow WA, Grocott A, McWilliams KA, Ruohoniemi JM, Yeoman TK, Dyson PL, Greenwald RA, Kikuchi T, Pinnock M, Rash JPS, Sato N, Sofko GJ, Villain J-P, Walker ADM (2007) A decade of the Super Dual Auroral Radar Network (SuperDARN): scientific achievements, new techniques and future directions. Surv Geophys 28:33-109. doi:10.1007/ s10712-007-9017-8

Chisham G, Yeoman TK, Sofko GJ (2008) Mapping ionospheric backscatter measured by the SuperDARN HF radars-part 1: a new empirical virtual height model. Ann Geophys 26:823-841

Yeoman TK, Chisham G, Baddeley LJ, Dhillon RS, Karhunen TJT, Robinson TR, Senior A, Wright DM (2008) Mapping ionospheric backscatter measured by the SuperDARN HF radars - part 2: assessing SuperDARN virtual height models. Ann Geophys 26:843-852

Davies K (1990) Ionospheric radio. Peter Peregrinus Ltd, London

Grocott A, Hosokawa K, Ishida T, Lester M, Milan SE, Freeman MP, Sato N, Yukimatu AS (2013) Characteristics of medium-scale traveling ionospheric disturbances observed near the Antarctic Peninsula by HF radar. J Geophys Res Space Phys 118:5830-5841

He L-S, Dyson P, Parkinson ML, Wan W (2004) Studies of medium scale travelling ionospheric disturbances using TIGER SuperDARN radar sea echo observations. Ann Geophys 22:4077-4088

Hughes JM, Bristow WA, Greenwald RA, Barnes RJ (2002) Determining characteristics of HF communications links using SuperDARN. Ann Geophys 20:1023-1030

Karhunen TJT, Robinson TR, Arnold NF, Lester M (2006) Determination of the parameters of travelling ionospheric disturbances in the high-latitude ionosphere using CUTLASS coherent scatter radars. J Atmos Solar-Terrestrial Phys 68:558-567. doi:10.1016/j.jastp.2005.03.021

Kurkin VI, Orlov II, Ponomarchuk SN (1990) A scheme for calculating characteristics of HF-signals scattered by localized irregularities in the Earth-ionosphere waveguide. Res Geomagn Aeronomy Solar Phys 92:116-121 (in Russian)

McDonald AJ, Whittington J, de Larquier S, Custovic E, Kane TA, Devlin JC (2013) Elevation angle-of-arrival determination for a standard and a modified superDARN HF radar layout. Radio Sci 48:709-721. doi:10.1002/2013RS005157

Milan SE, Jones TB, Robinson TR, Thomas EC, Yeoman TK (1997) Interferometric evidence for the observation of ground backscatter originating behind the CUTLASS coherent HF radars. Ann Geophys 15:29-39

Oinats AV, Kurkin VI, Kutelev KA, Nishitani N (2012) The outlook of SuperDARN radars application for monitoring of the ionospheric dynamics in Russia. Phys BI 1(3):3-18 (in Russian)

Oinats AV, Kurkin VI, Nishitani N (2015) Statistical study of medium-scale traveling ionospheric disturbances using SuperDARN Hokkaido ground backscatter data for 2011. Earth Planets Space 67:22. doi:10.1186/s40623-015-0192-4

Ponomarenko P, Nishitani N, Oinats AV, Tsuya T, St-Maurice J-P (2015) Application of ground scatter returns for calibration of HF interferometry data. Earth Planets Space 67:138. doi:10.1186/s40623-015-0310-3

Samson JC, Greenwald RAA, Ruohoniemi JM, Frey A, Baker KB (1990) Goose Bay radar observations of Earth-reflected, atmospheric gravity waves in the highlatitude ionosphere. J Geophys Res 95(A6):7693-7709

\section{Submit your manuscript to a SpringerOpen ${ }^{\circ}$ journal and benefit from:}

- Convenient online submission

- Rigorous peer review

- Immediate publication on acceptance

- Open access: articles freely available online

- High visibility within the field

- Retaining the copyright to your article

Submit your next manuscript at $>$ springeropen.com 